\title{
Whole heart self-navigated 3D radial MRI for the creation of virtual 3D models in congenital heart disease
}

\author{
Nicole Wake ${ }^{1,2^{*}}$, Li Feng ${ }^{1}$, Davide Piccini ${ }^{3}$, Larry A Latson ${ }^{1}$, Ralph S Mosca ${ }^{4}$, Daniel K Sodickson ${ }^{1}$, Puneet Bhatla ${ }^{1,5}$ \\ From 19th Annual SCMR Scientific Sessions \\ Los Angeles, CA, USA. 27-30 January 2016
}

\section{Background}

Three-dimensional (3D) virtual models are valuable tools that may help to better understand complex cardiovascular anatomy and facilitate surgical planning in patients with congenital heart disease (CHD). Although computed tomography (CT) images are used most commonly to create these models [1,2], Magnetic Resonance Imaging (MRI) may be an attractive alternative, since it offers superior soft-tissue characterization and flexible image contrast mechanisms, and avoids the use of ionizing radiation. However, segmentation on MRI images is inherently challenging due to noise/artifacts, magnetic field inhomogeneity, and relatively lower spatial resolution compared to CT. The purpose of this study was to evaluate the image quality and assess the feasibility of creating virtual 3D heart models using a novel prototype 3D whole heart self-navigated radial MRI technique.

\section{Methods}

Free-breathing self-navigated whole heart MRI was performed on three pediatric patients: two with complex CHD (average age $=17$ months) and one with normal cardiac anatomy (age $=17$ years), using a 3D radial, nonslice-selective, $\mathrm{T}_{2}$-prepared, fat-saturated bSSFP sequence on a 1.5T MRI scanner (MAGNETOM Aera, Siemens, Germany). The acquisition window ( $50-55 \mathrm{~ms})$ was placed in mid-diastole and was adapted for different heart rates. Imaging parameters were as follows: TR/ $\mathrm{TE}=3.1 / 1.56 \mathrm{~ms}$, FOV $=200 \mathrm{~mm}^{3}$, voxel size $=1 \mathrm{~mm}^{3}$, $\mathrm{FA}=115^{\circ}$, and acquisition time $=5-6$ minutes $(\sim 12000$ radial lines). Respiratory motion correction and image

\footnotetext{
${ }^{1}$ Center for Advanced Imaging Innovation and Research (CAI2R) and Bernard and Irene Schwartz Center for Biomedical Imaging, Department of Radiology, New York University School of Medicine, New York, NY, USA Full list of author information is available at the end of the article
}

reconstruction was performed on the scanner as described in [3]. For comparison, conventional non-gated 3D FLASH or navigator-gated 3D bSSFP sequences were also performed. All results were blinded and randomized for image quality assessment by one pediatric cardiologist and one cardiac radiologist using a five-point scale (1=non-diagnostic, $2=$ poor, 3 =adequate, 4 =good, $5=$ excellent). Statistical analysis was performed to compare mean scores. DICOM images were imported to a 3D workstation (Mimics, Materialise, Leuven, Belgium) for 3D post-processing. The cardiovascular anatomy was first segmented using a combination of automated and manual techniques; and volume rendering was performed to depict the anatomy of interest.

\section{Results}

The free-breathing self-navigated 3D radial acquisition provided significantly improved image quality and myocardial wall-blood contrast (Figure 1). Mean scores were 4.58 and 2.67 for the 3D radial and FLASH/bSSFP sequences respectively $(\mathrm{p}=0.003)$. The cardiovascular anatomy was well depicted on all virtual 3D models (Figure 2).

\section{Conclusions}

3D virtual models are frequently being created to understand complex anatomy, influence surgical planning, and provide intra-operative guidance for patients with $\mathrm{CHD}$. This novel free-breathing, self-navigated whole heart 3D radial sequence provided excellent image quality as compared to existing routine MR sequences. Furthermore, the superb image quality provided using this novel sequence makes it an excellent choice for the creation of 3D models. 

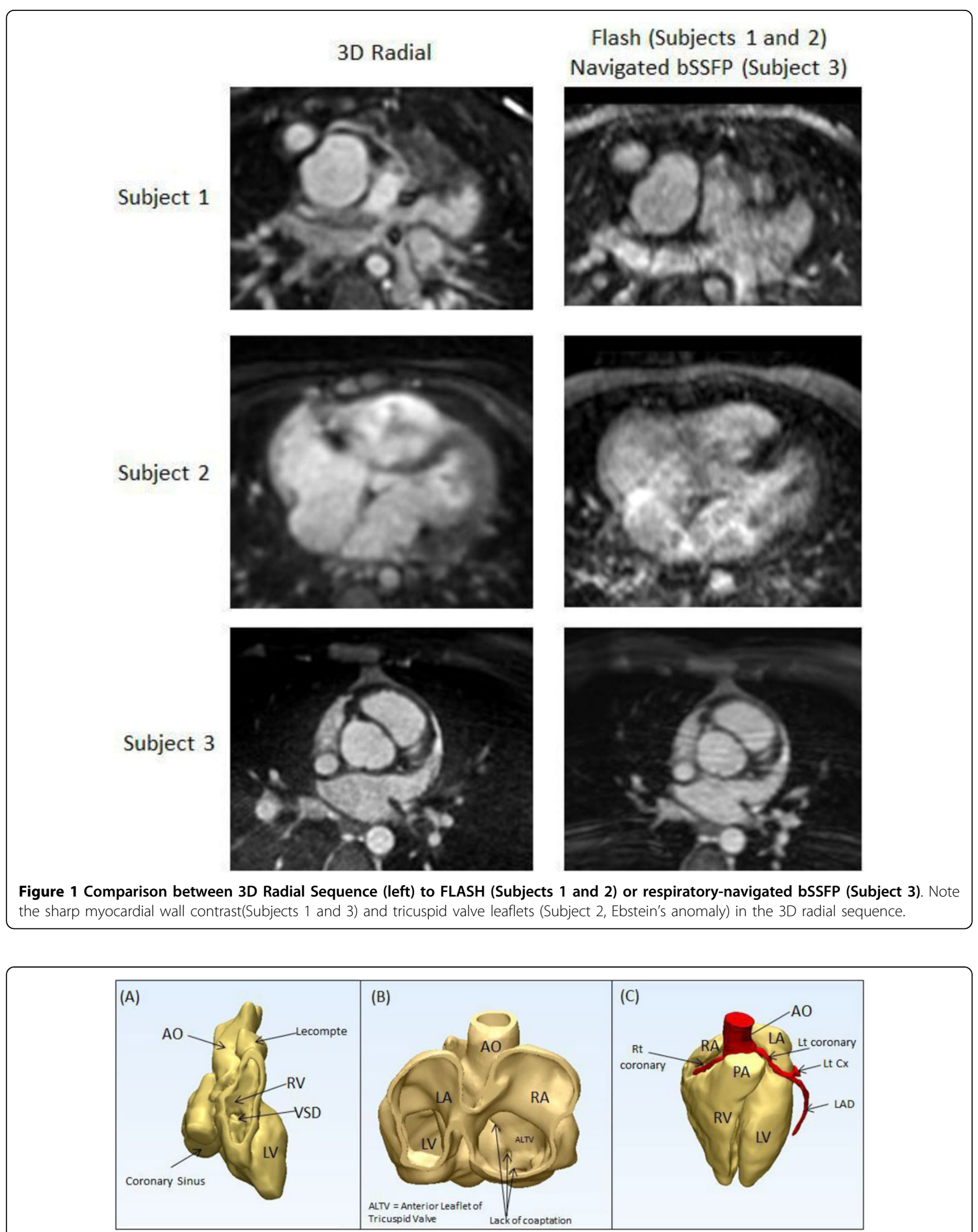

Figure 2 3D Virtual models demonstrating (A) arterial switch with lecompte, VSD, and enlarged coronary sinus in subject 1, (B) area of tricuspid regurgitation due to lack of coaptation in subject 2 (Ebstein's anomaly), and (C) normal cardiac anatomy and coronary arteries in subject 3 . 


\section{Authors' details}

${ }^{1}$ Center for Advanced Imaging Innovation and Research (CAI2R) and Bernard and Irene Schwartz Center for Biomedical Imaging, Department of Radiology, New York University School of Medicine, New York, NY, USA. ${ }^{2}$ The Sackler Institute of Graduate Biomedical Sciences, New York University School of Medicine, New York, NY, USA. ${ }^{3}$ Advanced Clinical Imaging Technology, Siemens Healthcare, Lausanne, Switzerland. ${ }^{4}$ Department of Cardiothoracic Surgery, New York University School of Medicine, New York, NY, USA. ${ }^{5}$ Department of Pediatrics, New York University School of Medicine, New York, NY, USA.

Published: 27 January 2016

doi:10.1186/1532-429X-18-S1-P185

Cite this article as: Wake et al:: Whole heart self-navigated 3D radial MRI for the creation of virtual 3D models in congenital heart disease.

Journal of Cardiovascular Magnetic Resonance 2016 18(Suppl 1):P185.

\section{Submit your next manuscript to BioMed Central} and take full advantage of:

- Convenient online submission

- Thorough peer review

- No space constraints or color figure charges

- Immediate publication on acceptance

- Inclusion in PubMed, CAS, Scopus and Google Scholar

- Research which is freely available for redistribution

Submit your manuscript at www.biomedcentral.com/submit 